\title{
Leaders
}

\section{Sport for people with a disability: the current state of play}

Sport for people with a disability has changed dramatically since the first recorded amputee race in 1880 when two men with cumbersome wooden limbs limped their way across the turf at Newmarket, a far cry from the highly tuned athletes competing at the Paralympics today. Currently the $100 \mathrm{~m}$ world record is 9.83 seconds, but the same distance has been run in 11.3 seconds by a bilateral foot amputee, and 10.7 seconds by an athlete with a shoulder disarticulation!

The name Paralympics means "parallel to the Olympics" not paralysed or paraplegic Olympics. As well as the more obvious wheelchair athletes, these games also include amputees and les autres ("the others"-for example, a congenital limb absence or an ankylosed joint), the visually impaired, athletes with cerebral palsy, and most recently some athletes with learning difficulties.

Great Britain has historically enjoyed a high level of success in disabled sport, largely as the result of the efforts of Sir Ludwig Guttmann, who identified the need for specialised rehabilitation for soldiers spinally injured in the second world war. He established a National Spinal Injuries Unit at Stoke Mandeville in 1944 and promoted the benefits of sport as an integrated part of rehabilitation. ${ }^{1}$ This has probably had a marked contribution to the increase in quality of life and life expectancy now enjoyed by the spinally injured. There is no longer a significant difference between life expectancy of able bodied and wheelchair users. There are still major concerns, however, with regard to the number of wheelchair users suffering from cardiovascular problems, particularly hypertension. ${ }^{2}$ It has been suggested that a more sedentary lifestyle, poor nutrition, and smoking are major causal factors, as they are with the general population. For the wheelchair user this is further exacerbated by difficulties with access to sports and recreation facilities, lack of wheelchair friendly kerbs, and in Britain, the inclement weather.

In the 1970s, the first reliable data on sports medicine and sports science for people with a disability started to be published. There have been several research papers relating to exercise physiology and cardiac function..$^{3-5}$ It can be seen from these that there are huge implications for the appropriate fitness assessment and training of wheelchair athletes, particularly the higher level spinal cord lesions. ${ }^{6}$ There are also difficulties with adaptation to extremes of temperature and travelling. Various papers have looked at the trends in injury statistics for disabled athletes, and it would appear that amputee athletes have a higher rate of low back pain than the general athletic population, which is probably due to unilateral forces and limb length discrepancies. Wheelchair users appear to suffer from more neck and shoulder injuries than able bodied athletes. This certainly seemed to be supported by figures from the Great Britain Paralympic team in Atlanta. The most frequent reason for seeking treatment was cervical spine dysfunction which referred symptoms to the shoulder. The constant sitting posture and lack of ability to rest the shoulder girdle and neck musculature aggravates this situation. There are implications for wheelchair design, preventive postural work, and technique modifications.

These studies are mostly fairly small scale, using small numbers of subjects or focusing on an individual country's team reports. However, it was suggested at the medical conference at the 1998 Winter Paralympics in Nagano, Japan, that there should be a coordinated approach to the collation of injury statistics from major games. If the individual teams were to submit their injury and treatment figures to a central organisation, it would allow a larger sample of injuries to be recorded and increase the statistical impact of the data. This could be the first step towards identifying real trends and directing further research.

History has given Great Britain and Northern Ireland a strong head start in the Paralympic movement, but it has also left us some difficulties. Disability organisations have in the past been at the forefront in sport, for example British Wheelchair Sport or the British Amputees and Les Autres Sports Association. In this scenario, a disability group - for example, a group of amputees-are brought together and then organised into separate sports within that group. The problem with this approach in today's sporting climate is that the standard of disabled sports performance now demands the very best of coaching, sports science, and sports medicine support. The only way to obtain the services of the experts in each sports specific field is to link with the national governing bodies of each sport. It is a much easier task for a top level coach to learn about an athlete's disability than for an expert in spinal injuries to learn how to coach a sport to the highest level. The same argument is true for doctors and physiotherapists; the top level disabled athlete now requires specialist sports medicine care. To this end, it is essential that further education in sports medicine includes disability specific information. This should relate to the specialist requirements for fitness assessment, training, treatment, travel, injury prevention, and other considerations, such as classification issues. Doctors and physiotherapists are specialised in examination techniques and are well equipped to establish accurately the extent of an athlete's disability. It would seem sensible to increase their involvement in the classification of disabled athletes.

Despite some lingering politics, the situation in Great Britain is now improving. Eight national squads are now lottery funded, which includes most Paralympic athletes. The lottery money is generally directed through the sports governing body. There are exceptions to this-for example, The British Athletics Federation have difficulties at the present time and so funds are temporarily directed through the British Paralympic Association (BPA). Boccia, wheelchair rugby, and goalball do not have an appropriate governing body to link with; the BPA are therefore likely to take on the responsibility for these sports in the short term. The governing bodies are responsible for pulling together squads and organising training, while the BPA is responsible for coordinating Paralympic Games and some of the World Championships. At grass roots level, home countries organisations such as the Scottish Sports Association for People with a Disability (SSAD) coordinate introduction to sport and sports development.

The UK Sports Council is working hard to promote this more effective structure, together with the English, Scottish, Welsh, and Northern Irish Sports Councils. It is essential that we do not sit on our laurels and be content with our performances in previous Paralympic Games. The 
rest of the world are chasing the pace, and it was obvious at the 1998 Winter Games that most countries were using specialised technicians, coaches, and sports medicine personnel, borrowed from their national able bodied teams. In the Summer Games, it is interesting that Australia have moved up from 5 th to 2 nd on the world medal table, picking up another 15 gold medals between Barcelona and Atlanta. It is just possible that this may be related to the complete integration of disabled sports persons into the Australian Institute of Sport. On the other hand, despite the huge amount of financial investment and available equipment in disabled sport in the United States, they dropped 20 gold medals, although still managed to hang on to the top position. The Americans like the British have a long history of disabled sport and difficulties in establishing effective coordination with national sports governing bodies. Great Britain dropped one place on the medal table between 1992 and 1996, managing a very creditable 39 gold medals, 42 silver, and 41 bronze in Atlanta; however, six of these medals were won in a sport that will not be included in the 2000 Games. The momentum needs to be kept up in order to continue development and maintain and improve the excellent performances of our athletes.

KIRSTY ARBUTHNOTT

Honorary Physiotherapist 1996, Paralympic Games

Classifier, World Organisation of Volleyball for the Disabled

Lecturer in Physiotherapy, Glasgow Caledonian University

1 Bloomfield PA, Fricker PA, Fitch KD. Textbook of science and medicine in sport Oxford: Blackwell Scientific Publications, 1992

Shephard RJ. Sports medicine and the wheelchair athlete. Sports Med 1998; $4: 226-47$

3 Figoni SF. Exercise responses and quadriplegia. Med Sci Sports Exerc 1993; 25:433-41.

4 Glaser RM. Arm exercise training for wheelchair users. Med Sci Sports Exerc 1989;21:149-57.

5 Langbein WE, Maki KC. Predicting oxygen uptake during counterclockwise arm crank ergometry in men with lower limb disabilities. Arch Phys Med Rehabil 1995;76:642-6.

6 Hoffman MD. Cardiorespiratory fitness and training in quadraplegics and paraplegics. Sports Med 1986;3:312-30.

\section{Lightning strikes: danger overhead}

Death by lightning is a rather uncommon event. In western societies nowadays, lightning deaths account for only one in a thousand trauma deaths, in contrast with the fairly common occurrence of lightning deaths in the early decades of this century (fig 1). This pronounced decrease is probably due to people moving from rural to urban areas, the development of caged farm machinery, the increased use of cars, and the construction of lightning conductors on houses and buildings. Although lightning casualties in the house have occasionally been described, ${ }^{1}$ the occurrence of lightning accidents is particularly related to outdoor activities. It is no longer the farmer, but the sporter and the hiker who are at risk during their recreational and explorative activities.
Most people are completely unaware of the danger that hangs over their heads when a thunderstorm is approaching $^{2-6}$; and when they do eventually realise the danger they are in, they display inadequate behaviour, such as seeking shelter in the wrong places.

When may lightning strike? Cherington has shown that it is possible to be struck by lightning miles and miles away from the centre of a thunderstorm, sometimes even as "a bolt from the blue". ${ }^{7}$ Therefore, the generally accepted safe distance $(3 \mathrm{~km})$ of 10 seconds between seeing the flash and hearing the thunder is only relatively safe. So hearing the thunder or seeing a flash is in itself reason enough to look for adequate shelter.

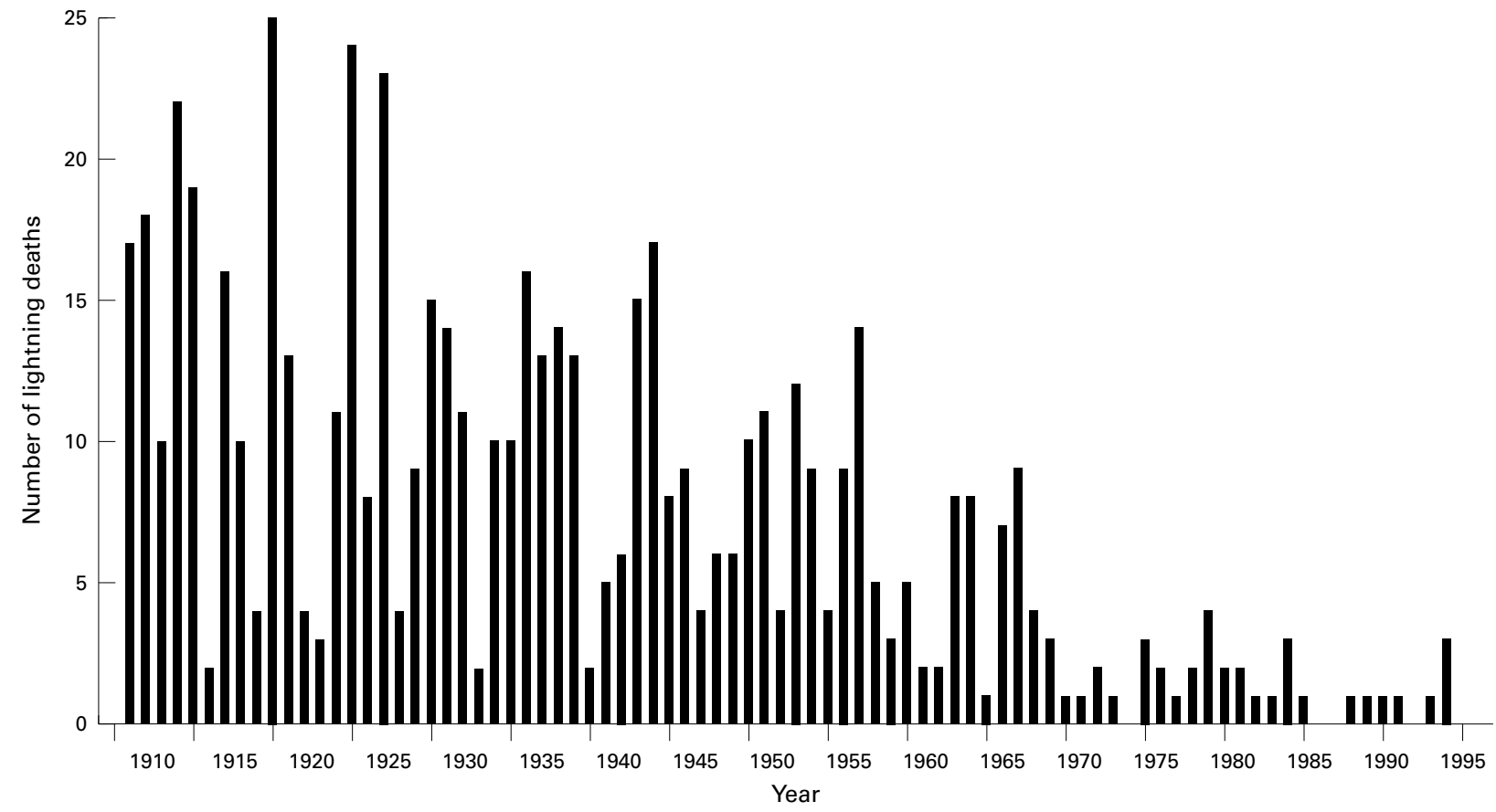

Figure 1 Number of lightning deaths in the Netherlands, 1910-95. 
Knowledge about how lightning can strike makes it possible to be inventive in finding a place of refuge.

\section{How lightning strikes}

One can be hit by lightning in four different ways. ${ }^{8}$ In the first place by a direct hit, occurring most often in open country. These are the places where there is little chance of finding shelter: the beach, the heath, and the slopes of mountains. As a standing person forms an ideal vertical conductor for a lightning discharge, one should try to avoid being the only exposed object in the vicinity. In this respect, a special warning should be given to those who use their sport equipment over their heads: golf clubs, fishing rods (carbon), mattocks, umbrellas and so on: the higher these "conductors" the greater the danger.

In most instances outdoor sport and recreational activities take place in environments with some shelter in the direct vicinity: big trees, forests, light masts, cabins; this is the second possible cause of a lightning hit. Numerous reports have been published on fatal accidents to sporters who shelter under freestanding trees. When incorrectly chosen these objects may form a threat to the person's life instead of offering some protection. ${ }^{5}{ }^{9}$ Why? When a tree is struck by lightning the resistance along the tree trunk between the ground and the head of the sheltering person may cause a potential difference which is greater than the breakdown strength of the air gap between the head/ shoulder region and the tree trunk. A flashover occurs (side flash) and the discharge current flows through the body into the ground. So people should keep away from tall freestanding objects, especially if they are not sure whether these objects are well earthed.

The third way a lightning discharge may cause injuries is through a step voltage. With step voltage there is a direct hit to the ground, whereafter the current runs through or over the ground in a centrifugal way; the distance depending on the composition of the soil. A rocky bottom is in general a good insulator, so the discharge may spread over a fairly long distance. This can be dangerous even at distances of over 20 metres from the point of impact.

A person can be hit by a step voltage in the following way: if he is standing or lying on the ground there may be a gap between two body parts in contact with the ground and the point of impact, such as both feet or a foot and hand/ arm. As a consequence, a potential difference can arise between those two body parts and cause a current to flow through the body. If a person is lying down, the current will flow through his trunk, whereas if he is standing up, the current will flow from one foot to the other via the waist.

Finally, one can be hit by contact voltage by being in direct contact with the discharge object/conductor.

\section{Type of injury}

What kind of injuries can be expected when a lightning discharge reaches the human body? The electricity can spread over the skin or it can enter the body. Obviously, both can occur at the same time and the predominant route taken by the current is influenced by many factors, such as applied voltage, resistance of the skin, etc. If the applied voltage is higher than the breakdown field of the skin, the whole discharge may penetrate the body. Not only small full thickness burns at the current entry or exit points but also organ disturbances can be expected along the current pathway. Cardiac arrest (asystole) and apnoea are the most commonly seen internal disturbances. It should be kept in mind that the heart often resumes its rhythm after a few minutes. The accompanying respiratory arrest is, however, often more long lasting, eventually leading to secondary arrest (fibrillation) due to hypoxia.

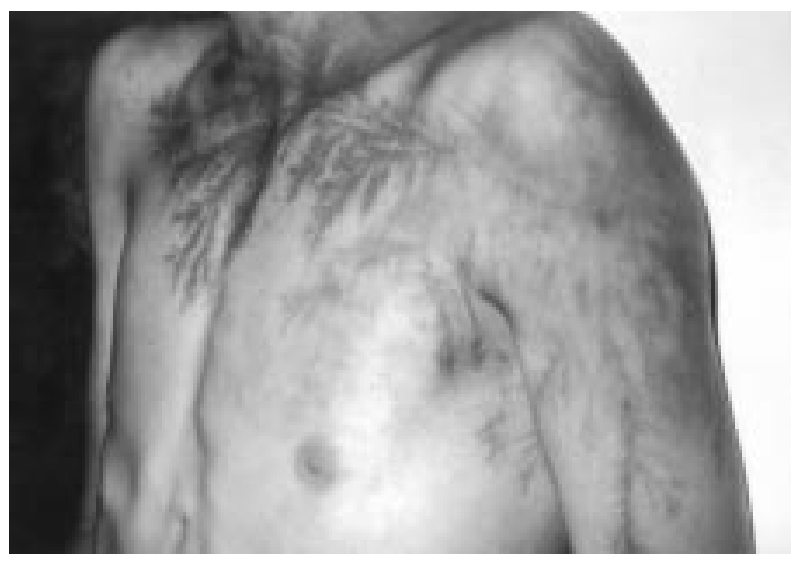

Figure 2 Fern-like skin marks after lightning strike in a 16 year old boy.

If the applied voltage does not immediately rise above the breakdown voltage of the skin, part of the current may flow over the skin causing splash burns and keraunographic markings, the so-called Lichtenberg figures (fig 2). ${ }^{8}$ The latter are pathognomonic for lightning accidents. These "arborescent" skin lesions tend to appear within an hour after the accident and generally disappear within 24 hours, without leaving any permanent marks. Their shape is tree-like or fern-like. The branches are bright red and contrast sharply with the surrounding skin. These figures are related to a positive electrical discharge. Comparable but differently shaped skin lesions that resemble the water drops coming from a shower head are related to negative discharges.

Of special interest is temporary paralysis of one or more extremities, most commonly the legs, in combination with complete or partial sensory loss, keraunoparalysis. ${ }^{9}$ In most cases there are signs of disturbed peripheral circulation: loss of pulse, extreme coolness, and pale or blue discoloration of the skin. As a rule, the disturbances disappear within 24 hours.

Most lightning victims will have lost consciousness and may present with combativeness or be confused, or both.

Other commonly seen lightning injuries are: tympanic rupture and eye damage (including cataract formation). Fractures and dislocation are relatively rare after lightning injuries. These only occur when the victim has been thrown some distance.

\section{Prevention}

As mentioned above, lightning may strike over a fairly long distance. Seek shelter when you hear the thunder or see the lightning, especially if you are in an exposed area. Do not carry electrical conductors above your head. Wearing metal objects on or around your body, however, does not increase the risk of being hit. ${ }^{10}$

Field players (soccer, hockey, golf, cricket, and so on): try to shelter in a stony building. Note that it is dangerous to be in a wooden cabin with an insulated metal roof. In such circumstances a lightning discharge in the vicinity may cause a potential difference between the heads of the sheltering sporters and the metal roof, which may become great enough to cause a flashover without the building being struck. ${ }^{11}$ Never shelter under freestanding trees because you may be hit by a side flash or contact voltage. Whenever possible, try to hide in the anonymity of a forest.

Mountaineers should try to find a place to hide somewhere in the face of the rocks, far away from the crests. Do not shelter in caves. Keep your metal objects with you, do not throw them away, do not raise your mattock above your head, avoid metal cables and metal ladders which you occasionally will find on difficult parts of the route. If there is any risk of a discharge over rocky ground, 
sit down on your rope or other insulating material. Hiding under metal foil (rescue blanket) does not offer any protection, it will melt completely if you are struck.

Hikers and campers: sheltering in a tent is very dangerous. If there are no other places to hide, for example a car or a bus (cage of Faraday), insulate yourself on an air mattress, keep as far away as possible from the tent poles. Do not lie down, keep your shoes on, and squat down.

Swimmers should immediately get out of the water, because a small current over the thorax in combination with the low resistance of wet skin may cause heart dysrhythmia and death.

Sailors on fibreglass or wooden ships should protect their ships with a lightning conductor through the stays of the mast and a thick metal cable hanging directly in the water.

For those who cannot find a place to shelter and are in immediate danger: make yourself as small as possible by squatting. In this way you lower the chance of being caught by a direct hit. By squatting with your feet together, you prevent a potential difference between two body parts that are in contact with the ground but are at different distances from the impact point. In this manner, a contact voltage accident can be prevented.

In general, be aware of the risks when a thunderstorm is approaching; do not panic; use your common sense.
Gröningen University Hospital

H J TEN DUIS

Department of Surgery, Traumatology

PO Box 30.001

9700 RB Gröningen

The Netherlands

1 Blanco-Pampín JM, Suárez Peñaranda JM, Rico Boquete R, et al. An unusual case of death by lightning. F Forensic Sci 1997;42:942-4.

2 Zack F, Hammer U, Klett I, et al. Myocardial injury due to lightning. Int $\mathcal{F}$ Legal Med 1997;110:326-8.

3 Çeliköz B, Işik S, Türegün M, et al. An unusual case of lightning strike: fullthickness burns of the cranial bones. Burns 1996;22:417-19.

4 Marcus MAE, Thijs N, Meulemans AIF. A prolonged but successul resuscitation of a patient struck by lightning. Eur f Emerg Med 1994;1:199-202.

5 Graber J, Ummenhofer W, Herion H. Lightning accident with eight victims: case report and brief review of the literature. $\mathcal{F}$ Trauma 1996;40:288-90.

6 Wetli CV. Keraunopathology: an analysis of 45 fatalities. Am F Forensic Med Pathol 1996;17:89-93.

7 Cherington M, Krider EP, Yarnell PR, et al. A bolt from the blue: lightning strike to the head. Neurology $1997 ; 48: 683-6$.

8 Duis HJ ten, Klasen HJ, Nijsten MWN, et al. Superficial lightning injuries their 'fractal' shape and origin. Burns 1987;13:141-6.

9 Duis HJ ten. Keraunoparalysis. In: Andrews CJ, Cooper MA, Darveniza M, et al, eds. Lightning injuries: electrical, medical and legal aspects. Boca Raton : CDC Press, 1992:86-7. (ISBN 08493 545.)

10 Gary C. La fondre. Des mythologies antiques à la recherche moderne. Paris: Massou, 1994. (ISBN 2-225-84507-7.)

11 Lee WR. Lightning injuries and death. In: Golde RH, ed. Lightning . Vol. 2. New York: Academic Press, 1977:521-43.

\section{Evidence based medicine in the musculoskeletal examination}

The use of evidence based medicine (EBM) in the musculoskeletal examination is limited at best. For many years we have relied on the recommendations of "experts" in the field in developing clinical examinations without validation by well designed studies. Despite the lack of validation we use these tests in making diagnoses and assessing treatment of musculoskeletal problems in sports medicine. In this time of cost containment in the medical field the use of sensitive and specific tests is imperative. ${ }^{12}$ Development of studies that can provide this crucial information is limited by the background of those using these tests, the design and clinical applicability of the study, and the cost of these studies.

For many years the use of a single musculoskeletal manoeuvre or battery of manoeuvres was used to make a specific musculoskeletal diagnosis or evaluate treatment. The positive predictive value of the test was verified anecdotally by surgical intervention. The negative predictive value was difficult to assess because rarely was there surgical intervention if the examination was not consistent with the diagnosis. The advent of radiographic techniques and their refinement to the present day magnetic resonance imaging (MRI) techniques has paved the way for the development of safer and more precise validation of our musculoskeletal clinical examination skills. Despite this, those who used the tests have failed to develop well designed studies to "test their tests". This is not because of lack of motivation or desire to improve their field. It probably represents the failure of the medical profession to teach EBM early in the practitioner's medical career. ${ }^{34}$ Because of this failure those in the sports medicine profession have never learnt to question unvalidated diagnostic tests. The more widespread institution of EBM curricula in the medical system and the addition of primary care specialties traditionally more versed in its use may help to alleviate this weakness. ${ }^{5}$
Of the very few studies that have been reported, many are poorly designed and have limited use. Most are retrospective studies as a result of a chart review, using multiple evaluators, having inconsistent examination techniques, or are biased by selecting only those who are surgical candidates. The majority evaluate a single musculoskeletal test. Provision of sensitivity, specificity, positive predictive value, and negative predictive value of a single diagnostic test is not nearly as helpful as providing this information on a battery of diagnostic tests in addition to each individual test. For instance, in the evaluation of instability of the shoulder the use of the clinical history, apprehension test, relocation test, load and shift test, sulcus sign, and the crank test are the mainstay of diagnosis. The use of each individual diagnostic method may prove lacking, though the use of all can be much more specific and sensitive as shown by Liu. ${ }^{6}$ Hertel provided similar information about rotator cuff tears. ${ }^{7}$ Having the information on the individual tests can be important in developing the test batteries.

Institution of well designed studies is severely limited by funding. With the advent of very precise MRI techniques, most surgical diagnoses can now be made without intervention. Comparing the clinical examination using this as the gold standard can easily provide the needed information on specificity, sensitivity, positive predictive value, and negative predictive value without the additional morbidity and mortality associated with surgical interventions. (Evaluation of tears in the glenoid labrum and meniscus of the knee are exceptions and may need surgical diagnosis, though MRI techniques are advancing. ${ }^{8}$ ) Funding for these studies, however, can be very expensive. Though the availability of grants for such projects is lacking, there are some sports medicine groups that do have such funding. ${ }^{89}{ }^{910}$ Expansion of such funding sources is sorely needed but slowly advancing. 
We can no longer blindly accept musculoskeletal examinations as valid without properly designed studies to support their use. Use of the existing data is possible only if one carefully scrutinises the study design, otherwise we risk making decisions based on incomplete data. ${ }^{211}{ }^{12}$ With the tools within our grasp, the only hurdle remaining is funding. Hopefully our sports medicine societies will continue to expand their support of such projects.

There are many journals, including this one, that have supported the use of EBM. ${ }^{13}$ Published articles that assist the clinician in incorporating EBM into their practice are available from many journals. ${ }^{514}{ }^{15}$ Hopefully, even those of us who predate EBM curricula can begin to use evidence based medicine more effectively in sports medicine (EBSM?).

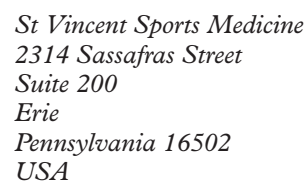

1 Jaeschke R, Guyatt GH, Sackett DL for the Evidence-Based Medicine Working Group. Users' guides to the medical literature. III. How to use an article about a diagnostic test. B. What are the results and will they help me in caring for my patients? $\mathcal{F} A M A 1994 ; 271: 703-7$.

2 McMaster University. How to read clinical journals: V. To distinguish useful from useless or even harmful therapy. Can Med Assoc f 1981;124:1156-62.
3 McMaster University: Evidence-based medicine. A new approach to teaching the practice of medicine. Evidence-Based Medicine Working Group [see comments]. $\mathcal{F} A M A$ 1992;268:2420-5.

4 Evidence-Based Care Resource Group. Evidence-based health care: a new approach to teaching the practice of health care. Evidence-Based Medicine Working Group [see comments]. F Dent Educ 1994;58:648-53.

5 McMaster University. How to read clinical journals: I. Why to read them and how to start reading them critically. Can Med Assoc f 1981;124:555-8.

6 Liu SH, Henry MH, Nuccion S, et al. Diagnosis of glenoid labral tears. A comparison between magnetic resonance imaging and clinical examinations [see comments]. Am F Sports Med 1996;24:149-54.

7 Hertel R, Ballmer FT, Lombert SM, et al. Lag signs in the diagnosis of rotator cuff rupture. F Shoulder Elbow Surg 1996;5:307-13.

8 Gusmer PB, Potter HG, Schatz JA, et al. Labral injuries: accuracy of detection with unenhanced MR imaging of the shoulder. Radiology 1996;200: 519-24.

8a Howard Hughes Medical Institute. GrantsNet. Howard Hughes Medical Institute internet site, 11 September 1998, http://www.grantsnet.org/

9 American College of Sports Medicine. Research grant opportunities. American College of Sports Medicine internet site, 26 September 1998, http://acsm.org/grant97.htm.

10 Campaigne BN. Research funding: where the money is. Sports Med Bull 1997;32:8.

11 Jaeschke R, Guyatt G, Sackett DL for the Evidence-Based Medicine Working Group. Users' guides to the medical literature. III. How to use an article about a diagnostic test. A. Are the results of the study valid? $f A M A$ 1994;271:389-91.

12 McMaster University. How to read clinical journals: II. To learn about a diagnostic test. Can Med Assoc F 1981;124:703-10.

13 Gillespie WJ, Handoll H. Evidence based medicine: the Cochrane Collaboration. Br f Sports Med 1997;31:172.

14 Oxman AD, Sackett DL, Guyatt GH for the Evidence-Based Medicine Working Group. Users' guides to the medical literature. I. How to get started. $\mathcal{F A M A}$ 1993;270:2093-5.

15 Evidence-Based Care Resource Group. Evidence-based care: 1. Setting priorities: how important is the problem? Can Med Assoc f 1994;150:124954 .

\section{Use of population attributable risk (PAR) in understanding the health benefits of physical activity}

Since the publication of the US Surgeon General's report in 1996, physical inactivity is widely considered a major risk factor for cardiovascular disease, diabetes, some cancers, and physical activity a method of improving musculoskeletal health and reducing anxiety and depression. ${ }^{1}$ Consistent epidemiological evidence, especially for preventing coronary heart disease (CHD), has been available for over a decade. ${ }^{2}$ Recent policy statements affirm that activating the sedentary is likely to lead to the greatest population health benefits. ${ }^{3}$

The relation between physical activity and most health outcomes is usually expressed as a relative risk (RR). This is calculated as the ratio of the rate of the outcome in those who are inactive compared with the outcome in those who are more active. For comparing the RR of CHD between the sedentary and the moderately active, an RR of about 2.0 has been estimated (pooled research confirms that the risk of incident or fatal CHD is about twice as high in the sedentary as in the active). ${ }^{24}$

The health burden imposed by physical inactivity can be better understood using the notion of population attributable risk (PAR). This is defined as the proportion of a given health outcome attributable to inactivity in the population. PAR depends on the risk of exposure (relative risk), and upon the prevalence of the risk factor in the population. The prevalence of insufficient physical activity for health in the Australian adult population is around 50\%. ${ }^{5}$ Among national studies of PAR prevalence, researchers use different methods for defining sedentariness and "insufficient activity". Where methods are similar, prevalence estimates are consistent, with $48 \%$ of adult Canadians and $45 \%$ of British adults meeting health related threshold criteria. ${ }^{6}$ More stringent survey measures estimate that between a quarter and a third of adults are "sufficiently active" in
Finland, Sweden, and the USA. ${ }^{16}$ All of these estimates rank the prevalence of physical inactivity as a leading risk factor for CHD compared with other recognised risk factors (hypertension, smoking, high cholesterol levels).

From the relative risks derived from epidemiological studies, and the prevalence of physical inactivity, the PAR percentage can be calculated. This is defined as the percentage of any health outcome in a population that is attributed to inactivity. ${ }^{7} \mathrm{~A}$ higher prevalence of inactivity in the population, or a stronger association between inactivity and a health outcome, will both result in a greater PAR. This concept has been used to estimate the proportion of deaths from CHD that might be prevented if the population became physically active; estimates between one quarter and one third of these deaths appear to be attributable to physical inactivity, ${ }^{58}$ and even small increases in physical activity participation in the whole population might decrease cardiac deaths by about $5 \%$.

The health benefits can be estimated for other conditions where the relative risk of physical inactivity is well documented by many epidemiological studies. Powell and Blair estimated that a third of deaths from colon cancer and diabetes were attributable to inactivity, and that around $4 \%$ of these might be averted if the modest changes to meet the Healthy People 2000 targets were achieved for physical activity in the USA. ${ }^{8}$

In addition, there are other disease states where the protective role of physical activity is apparent. One well designed case-control study has estimated that $12 \%$ of breast cancer risk is attributable to inactivity, especially among postmenopausal women. ${ }^{9}$

Population studies of risk factors for stroke suggest that about $15 \%$ of the risk may be attributable to lack of 
physical activity. ${ }^{10}$ A large multicentre case-control study of hip fracture suggested that $10-16 \%$ of the overall risk might be explained by physical inactivity. Thus one in six to one in 10 hip fractures might be prevented if the population were even moderately active. ${ }^{11}$

Physical activity, using the PAR approach, is seen as a major risk factor for cardiovascular disease, at least as important as other recognised risk factors. ${ }^{312}$ The association between risk factors and health outcomes is biologically fixed, ${ }^{8}$ and the only modifiable component is prevalence. For this reason we need to address the public health problem of inactivity with the same energy as we deal with the problem of tobacco control. The PAR approach is an extension of previous methods for appraising the magnitude of these potential benefits, and is useful in health advocacy for positioning physical inactivity as a major and underresourced health concern.

School of Community Medicine

ADRIAN BAUMAN

University of New South Wales

Sydney NSW 2052, Australia
1 US Department of Health and Human Services Physical Activity and Health. A report of the Surgeon General. US: Department of Health and
Human Services, Centers for Disease Control and Prevention, 1996.

2 Powell K Thompson P, Casperson C, et al. Physical activity and the incidence of coronary heart disease. Annu Rev Public Health 1987;8:25387.

3 Pate RR, Pratt M, Blair S, et al. Physical activity and public health: a the American College of Sports Medicine. $\mathcal{F A M A}$ 1995;273:402-7.

4 Berlin J, Colditz GA. A meta analysis of physical activity in the prevention of coronary heart disease. Am $\mathcal{F}$ Epidemiol 1990;132:612-28.

5 Bauman A, Bellew B, Booth M, et al. Towards best practice for the promotion of physical activity in areas of NSW. Sydney: Centre for Health Promotion and Disease Prevention, NSW Health Department, 1996.

6 Oja P. Descriptive epidemiology of health related physical activity and fitness. Res Q Exerc Sport 1995;66:303-12.

7 Hennekens CH, Buring JE. Epidemiology in medicine. Boston: Little Brown, 1987.

8 Powell KE, Blair SN. The public health burdens of sedentary living habits: theoretical but realistic estimates. Med Sci Sports Exerc 1994;26:851-6.

9 Mezzetti M, Lavecchia C, Decarli A, et al. Population attributable risk for breast cancer - diet, nutrition, and physical exercise. $\mathcal{F}$ Natl Cancer Inst 1998;90:389-94.

10 Shinton R. Lifelong exposures and the potential for stroke prevention - the contribution of cigarette smoking, exercise, and body fat. $\mathcal{F}$ Epidemiol Community Health 1997;51:138-43.

11 Johnell O, Allander E, Gullberg B, et al. Influence of lifestyle in the MEDOS study. Scand $\mathcal{F}$ Rheumatol Suppl 1996;103:112.

12 McGinnis JM, Foege WH. Actual causes of death in the United States. fAMA 1993;270:2207-12.

\section{Will antibiotics affect my sporting performance?}

In general the simple answer to this question is no, that antibiotics alone will not affect sporting performance. However, what will undoubtedly affect performance is the infection for which the antibiotic is being taken. However, there is one group of antibiotics which athletes might do well to avoid: the quinolone antibiotics, such as ciproflaxacin (Cipoxin), oflaxacin (Tarivid), and norfloxacin (Utinor). ${ }^{1}$ Other drugs of this type will become available in the future, but the problems appear to be common to all of them. ${ }^{2}$

The reason for this is that these antibiotics can cause inflammation of tendons and even tendon rupture. Ruptures of the Achilles tendon in particular but also of shoulder and hand tendons that required surgical repair or resulted in prolonged disability have been reported. These have particularly affected the elderly and those taking glucocorticoids, but cases have also occurred in otherwise healthy athletes. If a patient suffers pain or inflammation of any tendon while taking these drugs, the drug should be discontinued and the affected limb rested until the symptoms settle down.

These drugs are increasingly widely used, particularly for cystitis and other urinary infections but also for chest infections. They can usually be avoided since there is almost always a range of equally effective alternative drugs available.

Professor of Clinical Pharmacology,

TOM WALLEY

University of Liverpool

1 Anon. Tendon damage associated with quinolone antibiotics. Current Problems in Pharmacovigilance 1995;21:8.

2 Nightingale St. New fluoroquinolone warning label. fAMA 1996;276:774. 